\title{
Memantine: a review of studies into its safety and efficacy in treating Alzheimer's disease and other dementias
}

This article was published in the following Dove Press journal:

Clinical Interventions in Aging

25 September 2009

Number of times this article has been viewed

\author{
Stuart J Thomas \\ George T Grossberg \\ Department of Neurology \\ and Psychiatry, Saint Louis \\ University School of Medicine, \\ St. Louis, MO, USA
}

\begin{abstract}
Memantine is an uncompetitive N-methyl-D-aspartate receptor antagonist with moderate affinity. Its mechanism of action is neuroprotective and potentially therapeutic in several neuropsychiatric diseases. It has been approved by the FDA for the treatment of moderate to severe Alzheimer's disease (AD) either as a monotherapy or in combination with cholinesterase inhibitors. This review covers key studies of memantine's safety and efficacy in treating moderate to severe AD. It also covers current research into other dementias including but not exclusively mild AD and vascular dementia. Other studies on the efficacy of memantine for other neuropsychiatric diseases are discussed. Memantine is a safe and effective drug that merits further research on several topics. Clinicians should be aware of new studies and potential uses of memantine because of its safety and efficacy.
\end{abstract}

Keywords: memantine, Alzheimer's disease, dementia

\section{Introduction}

Memantine is an uncompetitive N-methyl-D-aspartate (NMDA) receptor antagonist with moderate affinity. Memantine was discovered in 1968 and patented by Eli Lilly. Merz later developed it in collaboration with Neurobiological Technologies, Inc. It was then licensed to Forest laboratories for development in the United States as well as Lundbeck for other international markets. The following are the proprietary names for memantine: Axura ${ }^{\circledR}$ and Akatinol ${ }^{\circledR}$ (Merz), Namenda ${ }^{\circledR}$ (Forest Laboratories), Ebixa ${ }^{\circledR}$ and Abixa $^{\circledR}$ (Lundbeck), and Memox ${ }^{\circledR}$ (Unipharm). ${ }^{1}$

Prior to the approval of memantine, treatment of Alzheimer's disease (AD) was limited to cholinesterase inhibitors (ChEI) for patients in the mild to moderate stages. There was no approved therapy for moderate to severe AD. New therapies for AD were eagerly pursued because of the rising numbers of patients suffering from the disease and progressing into the later stages. Due to the characteristic symptoms and progression of the disease, pathways involved in cognition, memory, and learning are commonly pursued as potential targets for treatment.

\section{Mechanism of action}

A central mechanism in learning and memory is long-term potentiation (LTP). LTP is mediated by the neurotransmitter glutamate via the NMDA receptor. The NMDA receptors can be found diffusely throughout the brain. However, they densely populate the dendrites of pyramidal cells in the hippocampus and cortex (areas known to be involved in cognition, learning, and memory). In addition to the relationship
Correspondence: George T Grossberg

I438 S. Grand Blvd., St. Louis,

MO 63104, USA

Tel + I 3 | 49774829

Fax + I 3149774878

Email grossbgt@slu.edu 
between LTP and learning, elevated glutamate levels are associated with excitotoxicity. Chronic low-dose administration of NMDA receptor agonists have been shown to induce apoptosis ${ }^{2,3}$ while high doses induce necrosis. ${ }^{3}$ The activation of glutamate receptors has also been found to induce the release of glutamate. Thus, a large build-up of glutamate can occur and induce a massive accumulation of $\mathrm{Ca}^{2+}$, leading to apoptosis. ${ }^{4}$ It was also noted that amyloid-beta (AB) plaques increase a neuron's vulnerability to excitotoxicity. ${ }^{5}$ $\mathrm{AB}$ plaques, a pathological feature of $\mathrm{AD}$, were found to induce depolarization of astrocytes, extracellular accumulation of glutamate, and intracellular deposition of $\mathrm{Ca}^{2+}{ }^{6}$ Therefore, the glutamate-induced excitotoxicity pathway made an excellent target for the therapy of AD.

Under physiologic conditions, the glutamate released by neurons is metabolized or taken up by neighboring cells. When these pathways are disrupted, the accumulated glutamate overexcites the NMDA receptor and induces pathology characteristic of neurodegenerative diseases. NMDA receptors act as a calcium [II] ion $\left(\mathrm{Ca}^{2+}\right)$ channel that activates when bound by glycine, glutamate, and/or NMDA. However, the channel functions only when the cell membrane is depolarized due to the blockade of the channel by the magnesium [II] ion $\left(\mathrm{Mg}^{2+}\right)$. This prevents the influx of $\mathrm{Ca}^{2+}$ when the neuron is at rest. Under pathological conditions, such as a chronically depolarized membrane, $\mathrm{Mg}^{2+}$ leaves the channel and neuronal metabolism is inhibited, leading to cell death. ${ }^{7}$ When this happens, the $\mathrm{Ca}^{2+}$ influx is unrestricted for a longer period of time than normal. This influx of $\mathrm{Ca}^{2+}$ contributes to an alteration of cell function, leading to cell death either through free radicals ${ }^{8}$ or through overload of the mitochondria, resulting in free radical formation, caspase activation, and the release of apoptosis-inducing factors. ${ }^{9}$ Antagonists to the NMDA vary in affinity and in site of action, resulting in different alterations to the channel. Regardless of the mechanism of action, antagonists decrease the permeability of the channel and prevent an influx of $\mathrm{Ca}^{2+}$. Thus NMDA receptor antagonists are looked to as possible neuroprotective agents and potential therapies for neurodegenerative disease.

Most NMDA antagonists are competitive antagonists and are not well tolerated by patients due to side effects, which can include hallucinations and schizophrenia-type symptoms. ${ }^{9}$ The side affects likely result from the competitive antagonists blocking physiological functions of the NMDA receptor. Its role in cognition, memory, and learning make it necessary that any drug using the NMDA receptor as a target of action must preserve physiologic function to be therapeutically useful.
Memantine acts on activated NMDA receptor by binding to a site located in the channel of the receptor. ${ }^{10}$ Memantine is a fast-binding antagonist which binds to the channel in a pseudo-first order manner. However, it is also dissociates from the receptor quickly and in a concentration independent manner. ${ }^{10}$ This allows the dose to affect the binding of memantine without affecting its removal from the site of action and allowing for increased potency with minimal side affects. In comparison with other antagonists, memantine has a much faster course of action and thus has less effect on physiologic mechanisms. For this reason, memantine offers a lot of promise in the therapy of neurodegenerative disease because it will preserve physiological function. ${ }^{11}$ In addition, the uncompetitive nature of the memantine's mechanism of action makes its antagonistic activity more potent in areas with massive activation of NMDA receptors. ${ }^{11}$ Memantine's mechanism of action is also voltage-dependent, which leads to the removal of the memantine blockage by depolarization of the membrane. ${ }^{12}$ All of these characteristics make memantine a strong candidate for treating pathology induced by excitotoxicity.

In several studies, memantine was found to prevent neuronal death induced via excitotoxic mechanisms. ${ }^{13,14}$ In 2003, memantine was approved for the treatment of moderate to severe AD in the US and in Europe. Approval for memantine permitted it to be used alone or in combination with ChEI. While it is currently in use for the therapy of moderate to severe $\mathrm{AD}$, other diseases and disorders are potential targets for therapy with memantine.

\section{Memantine in moderate to severe AD}

Three randomized, double-blind, placebo-controlled (RDBPC) trials were submitted to the FDA in the New Drug Application. ${ }^{15-17}$ These studies demonstrated memantine's safety and efficacy in moderate to severe AD.

The first of the studies submitted to the FDA evaluated memantine as a therapy for $\mathrm{AD}$ in a long-term care setting. ${ }^{15}$ In a placebo-controlled trial, patients were selected according to DSM-III criteria, a Mini-Mental State Examination (MMSE) score $<10$, and a Global Deterioration Scale (GDS) score of 5-7 $(n=166)$. The primary efficacy measures were the patient's response to therapy functionally and globally using the Behavioral Rating Scale for Geriatric Patients (BGP) and the Clinical Global Impression of Change (CGI-C). Administering $10 \mathrm{mg} /$ day (half the current recommended dosage) of memantine for 12 weeks, they documented statistically significant improvement in global 
and functional parameters. The measurements for behavior were not statistically significant. They also used Ferm's D-test as a secondary variable to determine efficacy and found that the treated patients needed less time for nursing care due to improved functionality. While no behavioral improvement was noted, the global and functional improvement demonstrated its value as a potential therapy for patients with moderate to severe AD.

In 2003, Reisberg et al conducted a similar study in an outpatient setting. ${ }^{16}$ These data were also submitted to the FDA. They used similar selection criteria with the addition of satisfying the diagnostic criteria of the National Institute of Neurologic and Communicative Disorders and Stroke and the Alzheimer's disease and Related Disorders Association (NINCDS-ADRDA). They administered memantine $10 \mathrm{mg}$ twice daily for 28 weeks at 32 US centers $(n=181)$. The study used the Severe Impairment Battery (SIB), the Clinician's Interview-Based Impression of Change plus Caregiver Input (CIBIC-Plus) as primary efficacy variables for cognition and global measurements, respectively. Secondary efficacy measures included the Alzheimer's Disease Cooperative Study Activities of Daily Living Inventory modified for severe dementia (ADCS-ADLsev) and the Neuropsychiatric Inventory (NPI) to measure impact on behavior. Patients receiving memantine showed statistically significant benefits when compared to placebo in both of the primary efficacy measures, the SIB and the CIBIC-Plus, over the 28-week trial. The patients receiving memantine also showed statistically significant improvement over placebo in the ADCS-ADLsev but not in the NPI. These results confirmed the results of the previous study with the addition of better cognitive outcomes for patients receiving memantine.

The third and final study submitted to the FDA was for a combination therapy of memantine and donepezil. Tariot et $\mathrm{al}^{17}$ conducted a RDBPC trial using 404 outpatients already on donepezil, from 37 US centers for 24 weeks with 322 patients completing the trial. Patients were selected according to the NINCDS-ADRDA diagnostic criteria for AD. They were also selected for MMSE scores between 5 and 14, age of at least 50 years and CT scans consistent with AD. Primary efficacy variables included cognition, using the SIB, and global measures, using the CIBIC-Plus. Secondary outcome measures were behavioral and functional. These were measured using the NPI and BGP, respectively. All patients remained on donepezil with half randomized to the addition of memantine and half to the addition of placebo. At the conclusion of the study, statistically significant benefits were found in all primary and secondary endpoint measures in favor of donepezil/memantine vs donepezil/placebo. Similar results were found in a study by van Dyck et al. ${ }^{18}$ This confirmed previous studies with the addition of improvement in behavioral outcomes.

Combination therapy is a promising choice of therapy for patients with moderate to severe AD. It is not currently approved by the FDA to treat mild AD with memantine so ChEI are the principal choice for treatment in mild cases. It has been shown that transition from a ChEI to memantine is well tolerated, ${ }^{19}$ but better outcomes may be achieved in patients receiving combination memantine/ $\mathrm{ChEI}^{17}$ so clinicians should add memantine to the patient's treatment plan without discontinuing the ChEI.

However, these principal studies showed conflicting outcomes on behavioral measurements. While Tariot et al demonstrated a positive outcome, ${ }^{17}$ Reisberg et al and Winblad et al had no statistically significant outcomes in measures of behavioral outcomes. ${ }^{15,16}$ Despite this inconsistency, memantine is a useful treatment for patients with moderate to severe $\mathrm{AD}$, but with behavioral disturbances common in patients with $\mathrm{AD}$ and those disturbances causing great distress to care givers, great interest lies in determining if memantine truly improves behavioral outcomes. Wilcock et al conducted a pooled analysis of 3 large 6-month studies of memantine using the NPI as an efficacy variable. They found a statistically significant improvement in behavioral outcomes, especially in measurements of agitation/aggression. ${ }^{20}$ Gauthier et al conducted a study with a shorter time period and a larger study group. ${ }^{21}$ This study used the NPI as well and also yielded statistically significant improvement in patients receiving memantine over those receiving placebo. These studies suggest that memantine may be a good treatment option for patients with AD and behavioral symptoms.

Finally, a study published in 2009 compiled memantine data from all clinical trials and from pivotal studies between 1992 and $2008^{16,17,23}$ for a post-hoc analysis. ${ }^{22}$ Patients in nursing homes or assisted living facilities were excluded because they have significantly different baselines. The study found that a meta-analysis of all the study groups showed statistically significant improvement in both the NPI and BGP for patients receiving memantine over placebo. However, the behaviors with statistically significant improvement were agitation/aggression, irritability/lability, and delusions Perhaps more importantly, this study found a delay in the emergence of behavioral symptoms with memantine vs placebo. Improvement in these measurements and prevention of emergence would ease the burden for care givers and increase the time to institutionalization. 
A large number of patients with $\mathrm{AD}$ are receiving antipsychotics, antidepressants, anxiolytics, or neuroleptics. ${ }^{22}$ These treatments are common due to the prevalence of behavioral symptoms in patients with $\mathrm{AD}$. One of the most prevalent behavioral symptoms is agitation and aggression. Memantine attenuates these symptoms very well and should be considered a principle treatment for AD patients experiencing agitation/aggression. ${ }^{21,22}$ Further studies should investigate the benefits of memantine vs other treatments in behavioral outcomes for patients with $\mathrm{AD}$.

Another critical point in the discussion of memantine as a treatment for $\mathrm{AD}$ is combination memantine/ChEI therapy. The study by Tariot et al demonstrated the efficacy of combination therapy in treating moderate to severe $\mathrm{AD} .{ }^{17}$ Another combination therapy study, by Atri et al demonstrated a long-term effect of combination therapy when compared with patients receiving no drug therapy and patients on cholinesterase monotherapy. ${ }^{24}$ Primary efficacy measures for cognition and function were the Blessed Dementia Scale (BDS) and the Weintraub Activities of Daily Living Scale (WADL). They found that even after a mean treatment time of 22.5 months, patients receiving combination therapy had significantly better outcomes than those receiving no pharmacotherapy or ChEI therapy alone. These data strongly favor the use of memantine/ChEI combination therapy in treating moderate to severe AD.

For many patients and their families, who are often care givers as well, staying out of long-term care facilities is a primary goal. A recent study conducted at the University of Pittsburgh evaluated 943 patients with probable $\mathrm{AD}$ and followed them long-term (mean time was $62.3 \pm 35.8$ months). ${ }^{25}$ They compared patients receiving memantine and ChEI with those receiving just $\mathrm{ChEI}$ and those receiving neither. They found that patients treated with $\mathrm{ChEI}$ had a decreased risk to institutionalization over those with no drug and the patients who received both memantine and ChEI had the greatest decrease risk (a decrease in risk over the ChEI monotherapy of 3.4). So while memantine/ChEI combination therapy may improve AD patients' outcomes cognitively, functionally, behaviorally, and globally, it may also help patients stay at home longer and delay time to institutionalization. ${ }^{25}$

Other studies of memantine/ChEI combination therapy have shown behavioral improvements, ${ }^{26}$ functional improvements, ${ }^{27}$ cognitive improvements, ${ }^{28,29}$ and a delay to institutionalization. ${ }^{25}$

It should be noted that one study with memantine found contradicting results when compared to previous studies. ${ }^{23}$ This study followed a similar protocol to the Reisberg Study. ${ }^{16,23}$ At weeks 12 and 18, a statistically significant improvement was detected in the CIBIC-plus but not at week 24. ADCS-ADL measurements failed to show statistically significant improvement. The SIB did not show statistically significant differences either until a nonparametric analysis was conducted post-hoc. The sample population was sufficiently large but the author pointed out possible confounding variables for future consideration. In van Dyck's study, $61 \%$ of his patients received prior ChEI therapy, which may have affected the outcome. A study comparing the response of patients grouped according to therapies received prior to memantine found that it affected the response to memantine treatment. ${ }^{30}$ van Dyck also pointed out that it is important to incorporate nonparametric analyses into the study design as a contingency plan. Finally, bias may be introduced utilizing the last observation carried forward (LOCF) method due to the significant results observed at weeks 12 and 18 but not at 24. Future investigations into memantine should consider previous therapy, nonparametric analyses, and the bias inherent in LOCF when designing the study.

While this conflicting study suggests some possible bias, many other studies have been conducted and demonstrated the positive effect on the progression of symptoms in patients with $\mathrm{AD}$ treated with memantine compared with placebo. ${ }^{31-33}$ More specifically, studies compared patients with moderate to severe $\mathrm{AD}$ receiving memantine to patients receiving placebo and evaluated them for benefits in cognition, ${ }^{34}$ function, ${ }^{35}$ behavior, ${ }^{20,21,36,37}$ and memory. ${ }^{38}$ In light of the abundance of data in support of memantine as a therapy for moderate to severe $\mathrm{AD}$, the contradictory study should be regarded as critical for future studies in order to avoid the possible biases pointed out by the author.

While these effects, combined with previous studies' results, strongly suggest the use of combination therapy in the treatment of moderate to severe $\mathrm{AD}$, studies evaluating its efficacy in comparison with memantine monotherapy have yet to be conducted or published. It seems safe to say that combination therapy would be at least as effective as monotherapy, if not more. However, a cost/benefit analysis would also be an invaluable tool in decision making for care givers and payers. Additional studies should consider comparing memantine monotherapy with cholinesterase monotherapy.

The data above are consistent with the guidelines published by the American Psychiatric Association (APA) and the American Association for Geriatric Psychiatry 
(AAGP). The guidelines recommend that clinicians consider the cost of treatment, severity of disease, and stage of progression prior to prescribing memantine. While data indicate that memantine is safe and effective as both a monotherapy and in combination with ChEI, no evidence suggests one is better than the other. However, memantine/ChEI combination therapy is more effective than some ChEIs alone and should be recommended over ChEI monotherapy.

\section{Memantine studies in mild AD}

Once an effect was seen in moderate to severe $\mathrm{AD}$, the next logical step was to investigate mild AD. This direction of study has provided mixed results. In a RDBPC study, researchers found that memantine produced statistically significant improvement in cognition, global measures, and behavior over placebo. ${ }^{39}$ There was no statistically significant difference between memantine and placebo on functional measures. These measures were assessed using the ADAS-Cog, CIBIC-plus, NPI, and ADCS-ADL, respectively.

In addition, two 24-week studies in 2008 found no statistically significant difference between memantine and placebo in measures of cognition (ADAS-cog) or in global measures (CIBIC-plus). ${ }^{40,41}$ One of the studies also used the ADCS-ADL and NPI as secondary efficacy measures of function and behavior, respectively, but memantine was not found to have a significant improvement in these measures either.

However, in the Bakchine study, the patients receiving memantine did show statistically significant improvement vs the control group at weeks 12 and 18 on the ADAS-Cog, but not at the end of the study. ${ }^{41}$ The authors attributed the lack of significance at week 24 to a sudden improvement in the control group. The results suggest that memantine may be a safe and effective therapy for patients with mild to moderate $\mathrm{AD}$ but further study is merited due to the conflicting studies. These future studies should include memantine/ChEI combination therapy and memantine vs ChEI comparison studies.

Consideration should be given to designing future studies for the use of memantine in treating mild AD. The uncompetitive mechanism of memantine suggests it may demonstrate more effect in more severe diseases. This was demonstrated in a study of vascular dementia ( VaD) when one subgroup responded better than another when grouped according to severity. ${ }^{42}$ Because it is of lesser severity than moderate to severe, a longer study with a larger study group is needed to detect any effect that memantine may or may not have in mild to moderate AD. In accordance with the treatment guidelines of the APA and AAGP, memantine should not be used unless future evidence suggests it is effective.

\section{Memantine in non-AD dementias}

The pivotal study by Winblad et al included both AD and VaD patients. A statistically significant effect was detected in both dementias ${ }^{15}$ and further studies have elaborated on memantine's efficacy in treating VaD. ${ }^{42-44}$ One of these studies was a 28 -week study with 321 patients. ${ }^{43}$ Using the ADAS-cog and CIBIC-plus as primary efficacy measures, the study found those measures stabilized in patients receiving memantine in comparison with placebo-treated patients. In addition, the treatment was well tolerated and there were no concerning side effects in this study. Memantine shows promise for the treatment of patients with VaD.

The next of those studies was a pooled analysis of several 6-month clinical trials measuring cognitive improvement using the ADAS-cog. ${ }^{42}$ Patients receiving memantine had statistically significantly better outcomes, with mild adverse effects. Post-hoc analysis revealed that the subgroup of $\mathrm{VaD}$, called 'small vessel disease,' accounted for the outcome of the experimental group while the 'large vessel disease' subgroup was not statistically significant when compared with placebo on its own. A study of memantine/ChEI combination therapy had similar results and conclusions. ${ }^{44}$

These studies make it clear that memantine has the potential to treat $\mathrm{VaD}$ but they also indicate what future studies need to consider. First, a group of patients diagnosed with $\mathrm{VaD}$ shows great heterogeneity and can easily be divided into subcategories. ${ }^{42,44}$ Second, the measures used to document the progression of the disease are designed for $\mathrm{AD}$ and may not be suitable for VaD. Finally, patients may suffer from both $\mathrm{VaD}$ and $\mathrm{AD}$ so sensitive neuroimaging of the brain may be necessary to screen for patients who are suffering from pure $\mathrm{VaD}$ without the amyloid plaques that are so common in $\mathrm{AD}$. These have to be considered to validate any effect that may or may not be detected in future studies.

Dementia with Lewy bodies (DLB) has also been studied as a potential target of memantine therapy. One RDBPC studyshowed a statistically significant improvement in cognition (MMSE) while showing no significant changes in the Parkinsonian or psychotic symptoms. ${ }^{45}$ This study suggests memantine may prove useful for DLB, but the study was short (16 weeks) and had relatively few 
subjects $(n=23)$. Further studies are merited to ensure the safety and efficacy of memantine in these patients. This is especially true since other small studies have shown adverse effects and worsening symptoms in patients with DLB receiving memantine. ${ }^{46,47}$

Other forms of dementia were also studied as potential targets of memantine therapy. One such disease is HIVassociated dementia. A 20 -week study found no statistically significant benefits. ${ }^{48}$ The author attributed the lack of a clinically significant result to the short duration of the study. However, they did find that indicators of neuronal metabolism suggest memantine may slow the destruction of neurons in patients with HIV.

A small study $(n=16)$ of Wernicke-Korsakoff syndrome found that patients receiving memantine showed statistically significant improvement in measures of cognition (MMSE) and function (ADCS-ADL) over patients receiving placebo during the course of the study ( 28 weeks). ${ }^{49}$ These results suggest memantine could be used but a larger study is needed.

Another study considered frontotemporal dementia (FTD) but found mixed results in measures of behavior, cognition, and global status, probably due to small sample size $(\mathrm{n}=16) .{ }^{50}$

The efficacy of memantine in treating any form of dementia in which glutamate-induced neurotoxicity is implicated should be considered for future study. The current research is limited by the small study groups so future studies should ensure that large numbers of patients are enrolled.

\section{Other studies with memantine}

Apart from dementia, many other diseases and disorders are associated with neurodegeneration. Studies in animals have suggested that memantine is neuroprotective ${ }^{51}$ but will still allow signaling and normal function. ${ }^{52,53}$ This is the reason memantine is clinically such a well tolerated drug. When administered to rats, researchers found it reduced neuronal deficits $^{54}$ by blocking NMDA receptors but it did not impair learning. ${ }^{55}$ Thus, it shows a lot of promise in treating acute as well as chronic brain disease. Animal studies found memantine was effective in ameliorating neuronal loss in infarctions, ${ }^{56}$ traumatic brain injury, ${ }^{57}$ hypoxic ischemic brain injury, ${ }^{58}$ intracerebral hemorrhage, ${ }^{59}$ mitochondrial dysfunction induced cell death, ${ }^{60}$ and secondary neuronal damage. ${ }^{61}$

Stroke research has looked at memantine as a neuroprotective agent to be administered both prior to the stroke event and afterwards. Studies have also found that memantine can lengthen the window to rescue neurons after the stroke event even if not administered before the stroke event. ${ }^{62,63}$ While research is still restricted to the animal model, it shows that memantine lengthens the therapeutic window when mixed with clenbuterol in the mouse model ${ }^{62}$ or mixed with nitrites in the rat model. ${ }^{63}$ Another study in the rabbit model demonstrated a potential amelioration of behavioral deficits when administered after a stroke event. ${ }^{64}$ These benefits are likely the result of memantine preventing the secondary excitotoxicity induced by lysis of glutamate-releasing neurons in the initial event.

A pilot study examined memantine as a treatment for patients suffering from combat-related post-traumatic stress disorder (PTSD). ${ }^{65}$ Four patients were treated with memantine and evaluated for immediate memory, delayed memory, hyperarousal, and depression. There was a uniform response in all the cases in delayed memory and variable reductions in hyperarousal and depressive symptoms. While the small study size and lack of a placebo control prevents these data from bearing any significance clinically, it does provide a rationale for further studies on using memantine as a therapy in patients with PTSD.

Researchers have also looked at memantine as a potential therapy for Parkinson's disease (PD). Studies have shown potential therapeutic benefits for patients with PD treated with memantine. ${ }^{66,67}$ However, the mechanism of action is unclear and is likely independent of dopaminergic therapies. ${ }^{68}$ This alternative therapeutic action of memantine in PD could shed light on the pathology of PD if investigated further. Further studies are merited.

Memantine has also been considered as a potential analgesic for chronic pain. NMDA receptors are thought to be involved in stimulus-invoked pain following nerve damage. Many patients experience chronic pain following surgery, amputation, or severe trauma. Studies have now shown that memantine has no analgesic affect for patients suffering chronic pain following surgery, ${ }^{69}$ post-herpetic neuropathy, ${ }^{70} \mathrm{HIV}$-associated neuropathy, ${ }^{71}$ and cannot ameliorate phantom limb pain. ${ }^{72-74}$ However, memantine has been reported to decrease the intensity of phantom limb pain when administered postoperatively. ${ }^{72}$ In addition, patients who suffer traumatic injury to an upper extremity and are administered memantine show a decrease in pain and some cortical reorganization on a functional MRI. ${ }^{75}$ While further investigations into the primary analgesic affects of memantine on chronic pain may be unwarranted, treatment of complex regional pain syndrome and phantom limb pain with memantine merit further study. 
Memantine has also been investigated as a potential therapy for refractory migraines. ${ }^{76}$ This study showed a decrease in the incidence of refractory migraines in patients taking memantine for a 30-month period. These positive results suggest that memantine is a potential therapy and merits further study.

Additional studies suggest memantine may possibly benefit patients with depression, ${ }^{77,78}$ binge eating disorder, ${ }^{79}$ schizophrenia, ${ }^{80,81}$ autism, ${ }^{82,83}$ attention-deficit/hyperactive disorder (ADHD),${ }^{84}$ nystagmus, ${ }^{85}$ Huntington's disease, ${ }^{86,87}$ and opioid dependence. ${ }^{88}$

In contrast, some studies suggest memantine offers little or no benefit to patients with tinnitus, ${ }^{89}$ cocaine dependence, ${ }^{90,91}$ and nicotine dependence. ${ }^{92}$

Results of studies of memantine's efficacy in alcohol dependence were mixed. ${ }^{93-95}$

Several diseases and disorders are currently being studied in clinical trials (Table 1) or have been studied in recently completed trials (Table 2).

\section{New formulation of memantine}

A clinical trial has recently been completed with a new $28 \mathrm{mg}$, slow-release memantine preparation in moderate to severe AD. Statistically significant benefits were seen on both primary efficacy measures (SIB and global). This 6-month RDBPC study also included a 6-month open-label followup. Memantine was well tolerated with side effects similar to those of placebo. ${ }^{97}$

Table I According to the National Institute of Health website, ${ }^{96}$ these diseases are being studied in clinical trials currently being conducted

\begin{tabular}{ll}
\hline Diseases being considered in current clinical trials \\
\hline Aphasia resulting from stroke & ADHD \\
Alcohol consumption & Opioid and heroine dependency \\
Traumatic brain injury & Multiple sclerosis \\
Moderate to severe AD & Compulsive buying \\
Frontotemporal dementia & Kleptomania \\
Bipolar disorder & Depressive disorder \\
Bipolar depression & Neurological symptoms \\
& of fragile X syndrome \\
Autism & Huntington's disease \\
Pathological gambling & Essential tremors \\
General anxiety disorder & Amytrophic lateral sclerosis \\
Social anxiety disorder & Down's syndrome \\
Shizophrenia & Tobacco abuse \\
Several types and subtypes & Chronic orthostatic intolerance \\
of dementia & \\
\hline
\end{tabular}

Table 2 According to the National Institute of Health website, ${ }^{96}$ these diseases were studied in completed clinical trials

\begin{tabular}{ll}
\hline Diseases considered in completed clinical trials \\
\hline Amyotrophic lateral sclerosis & AIDS dementia complex \\
Mild to moderate AD & Depression \\
Lupus erythematosus & Depressive disorder \\
Parkinson's disease dementia & Tension-type headache \\
Dementia with lewy bodies & Binge-eating disorder \\
Parkinson's disease & Side effects of radiation \\
& therapy for brain tumors \\
Co-morbid alcoholism & Neuropathy secondary \\
and depression & to herpes-zoster \\
Schizophrenia & Diabetic neuropathy \\
Obssessive-compulsive disorder & Open-angle glaucoma \\
\hline
\end{tabular}

\section{Safety profile}

Current recommended dosing for memantine in patients with $\mathrm{AD}$ is $10 \mathrm{mg}$ twice daily as a target dose. Dosing is increased at weekly increments from $5 \mathrm{mg}$ once daily to $5 \mathrm{mg}$ twice daily to $10 \mathrm{mg}$ once a day, and $5 \mathrm{mg}$ once a day to $10 \mathrm{mg}$ twice daily. Studies into once daily dosing show it to be comparatively mild and well tolerated with similar efficacy. ${ }^{98}$

Memantine is a well tolerated drug with few patients receiving memantine discontinuing therapy compared with patients receiving placebo. ${ }^{15-17,23}$ One study found that approximately $10 \%$ of patients administered memantine experienced a fall or injury during the study ${ }^{99}$

The following side effects occur in more than $2 \%$ of patients and at a greater frequency (not statistically significant) than in placebo-treated patients during clinical trials: fatigue, pain, hypertension, dizziness, headache, constipation, vomiting, back pain, confusion, somnolence, hallucination, coughing, dyspnea, agitation, fall, inflicted injury, urinary incontinence, diarrhea, bronchitis, insomnia, urinary tract infection, influenza-like symptoms, abnormal gait, depression, upper respiratory tract infection, anxiety, peripheral edema, nausea, anorexia, and arthralgia. ${ }^{100}$

Memantine has also been found to have antagonistic effects on type 3 serotonin receptors through the use of patch clamping. ${ }^{101}$ Memantine's 5HT-3 antagonism may protect against the gastrointestinal side effects of ChEIs when used in combination therapy.

Memantine undergoes both hepatic and renal elimination. In patients with severe impairment of either the liver or kidney, clinicians should prescribe a lower dosage of memantine accordingly. In patients with mild to moderate 
renal impairment, no adjustment is necessary. However, in patients with severe renal impairment, it is recommended that dosage not exceed $5 \mathrm{mg}$ twice daily. Drugs affecting renal secretion through altering the $\mathrm{pH}$ of the urine will affect memantine's clearance. Acidic urine will increase the rate of clearance while urine under alkaline conditions will undergo clearance at $80 \%$ of the rate at physiologic conditions. Memantine's bioavailability is not significantly affected by co-administration with other drugs that undergo renal excretion or hepatic elimination. It does not significantly induce or inhibit hepatic microsomal enzymes.

\section{Conclusion}

Research into further uses of memantine in the therapy of central nervous system disorders is merited by the nature of the drug's mechanism. The partial selectivity for antagonizing pathologically activated NMDA receptors makes this drug a therapeutic candidate for many neurodegenerative/neuropsychiatric diseases. Future studies into dementias other than moderate to severe AD (VaD, HIV-associated dementia, DLB) are needed to determine memantine's safety and efficacy in treating those diseases. In addition, neurodegenerative/neuropsychiatric disorders, such as PD, Huntington's disease, and schizophrenia need closer investigation with memantine both to improve clinical outcomes and to clarify the pathogenesis of disease. Clinicians should closely follow future research into memantine.

While memantine has potential to treat many different diseases, it should be considered early in the treatment of moderate to severe AD. It has strong evidence supporting its use both as a monotherapy and in combination with ChEI. Since there is a lack of other treatment options in moderate to severe $\mathrm{AD}$, memantine should be prescribed, barring intolerance or complications.

\section{Disclosures}

The authors declare no conflicts of interest.

\section{References}

1. Windholz M, editor. The Merck Index. 14th ed. New Jersey: Merck \& Co; 2006.

2. Dreyer EB, Zhang D, Lipton SA. Transcriptional or translational inhibition blocks low dose NMDA-mediated cell death. Neuroreport. 1995;6(6):942-944.

3. Bonfoco E, Krainc D, Ankarcrona M, Nicotera P, Lipton SA. Apoptosis and necrosis: two distinct events induced, respectively, by mild and intense insults with N-methyl-D-aspartate or nitric oxide/superoxide in cortical cell cultures. Proc Natl Acad Sci U S A. 1995;92(16): $7162-7166$.
4. Sucher NJ, Lipton SA, Dreyer EB. Molecular basis of glutamate toxicity in retinal ganglion cells. Vision Res. 1997;37(24):3483-3493.

5. Koh JY, Yang LL, Cotman CW. Beta-amyloid protein increases the vulnerability of cultured cortical neurons to excitotoxic damage. Brain Res. 1990;533(2):315-320.

6. Harkany T, Abraham I, Timmerman W, et al. Beta-amyloid neurotoxicity is mediated by a glutamate-triggered excitotoxic cascade in rat nucleus basalis. Eur J Neurosci. 2000;12(8):2735-2745.

7. Zeevalk GD, Nicklas WJ. Evidence that the loss of the voltage-dependent $\mathrm{Mg}^{2+}$ block at the N-methyl-D-aspartate receptor underlies receptor activation during inhibition of neuronal metabolism. $J$ Neurochem. 1992;59(4):1211-1220.

8. Lipton SA, Nicotera P. Calcium, free radicals and excitotoxins in neuronal apoptosis. Cell Calcium. 1998;23(2-3):165-171.

9. Lipton SA. Paradigm shift in neuroprotection by NMDA receptor blockade: memantine and beyond. Nat Rev Drug Discov. 2006;5(2):160-170.

10. Chen HS, Lipton SA. Mechanism of memantine block of NMDAactivated channels in rat retinal ganglion cells. J Physiol. 1997;499(Pt 1): $27-49$.

11. Chen HS, Pellegrini JW, Aggarwal SK, et al. Open-channel block of N-methyl-D-aspartate (NMDA) responses by memantine: therapeutic advantage against NMDA receptor-mediated neurotoxicity. J Neurosci. 1992;12(11):4427-4436.

12. Bresink I, Benke TA, Collett VJ, et al. Effects of memantine on recombinant rat NMDA receptors expressed in HEK 293 cells. $\mathrm{Br} J$ Pharmacol. 1996;119(2):195-204.

13. Vorwerk CK, Lipton SA, Zurakowski D, Hyman BT, Sabel BA, Dreyer EB. Chronic low-dose glutamate is toxic to retinal ganglion cells. Toxicity blocked by memantine. Invest Ophthalmol Vis Sci. 1996;37(8):1618-1624.

14. Pellegrini JW, Lipton SA. Delayed administration of memantine prevents N-methyl-D-aspartate receptor-mediated neurotoxicity. Ann Neurol. 1993;33(4):403-407.

15. Winblad B, Poritis N. Memantine in severe dementia: results of the $9 \mathrm{M}$-Best Study (Benefit and efficacy in severely demented patients during treatment with memantine). Int J Geriatr Psychiatry. 1999;14(2):135-146.

16. Reisberg B, Doody R, Stoffler A, et al. Memantine in moderate-to-severe Alzheimer's disease. $N$ Engl J Med. 2003;348(14):1333-1341.

17. Tariot PN, Farlow MR, Grossberg GT, et al. Memantine treatment in patients with moderate to seere Alzheimer's disease already receiving donepezil: a randomized controlled trial. JAMA. 2004;291(3): 317-324.

18. van Dyck CH, Schmitt FA, Olin JT; Memantine MEM-MD-02 Study Group. A responder analysis of memantine treatment in patients with Alzheimer disease maintained on donepezil. Am J Geriatr Psychiatry. 2006;14(5):428-437.

19. Waldemar G, Hyvarinen M, Josiassen MK, Korner A, Lehto H, Wtterberg P. Tolerability of switching from donepezil to memantine treatment in patients with moderate to severe Alzheimer's disease. Int J Geriatr Psychiatry. 2008;23(9):979-981.

20. Wilcock GK, Ballard CG, Cooper JA, Loft H. Memantine for agitation/ aggression and psychosis in moderately severe to severe Alzheimer's disase: a pooled analysis of 3 studies. J Clin Psychiatry. 2008;69(3): 341-348.

21. Gauthier S, Loft H, Cummings J. Improvement in behavrioural symptoms in patients with moderate to severe Alzheimer's disease by memantine: a pooled data analysis. Int J Geriatr Psychiatry. 2008;23(5):537-545.

22. Grossberg GT, Pejovic V, Miller ML, Graham SM. Memantine therapy of behavioral symptoms in community-dwelling patients with moderate to severe Alzheimer's disease. Dement Geriatr Cogn Disord. 2009;27(2):164-172.

23. van Dyck CH, Tariot PN, Meyers B, Malca Resnick E; for the Memantine MEM-MD-01 Study Group. A 24-week randomized, controlled trial of memantine in patients with moderate-to-severe Alzheimer disease. Alzhiemer Dis Assoc Disord. 2007;21(2):136-143. 
24. Atri A, Shaughessy LW, Locascia JJ, Growdon JH. Long-term course and effectiveness of combination therapy in Alzheimer's disease. Alxheimer Dis Assoc Disord. 2008;22(3):209-221.

25. Lopez OL, Becker JT, Wahed AS, et al. Long-term effects of the concomitant use of memantine with cholinesterase inhibition in Alzheimer disease. J Neurol Neurosurg Psychiatry. 2009;80(6):600-607.

26. Cummings JL, Schneider E, Tariot PN, Graham SM; Memantine MEM-MD-02 Study Group. Behavioral effects of memantine in Alzheimer disease patients receiving donepezil treatment. Neurology. 2006;67(1):57-63.

27. Feldman HH, Schmitt FA, Olin JT; Memantine MEM-MD-02 Study Group. Activities of daily living in moderate-to-severe Alzheimer disease: an analysis of the treatment effects of memantine in patients receiving stable donepezil treatment. Alzheimer Dis Assoc Disord. 2006;20(4):263-268.

28. Schmitt FA, van Dyck CH, Wichems CH, Olin JT; for the Memantine MEM-MD-02 Study Group. Cognitive response to memantine in moderate to severe Alzheimer disease patients already receiving donepezil: an exploratory reanalysis. Alzheimer Dis Assoc Disord. 2006;20(4):255-262.

29. Riepe MW, Adler G, Ibach B, Weinkauf B, Tracik F, Gunay I. Domainspecific improvement of cognition on memantine in patients with Alzheimer's disease treated with rivastigmine. Dement Geriatr Cogn Disord. 2007;23(5):301-306.

30. Dautzenberg PL, Wouters CJ, Bootsma JE. Observations from a 14-week open-label trial with memantine suggest variable response on behavioral symptoms and cognition, depending on former treatment of AD. Int Psychogeriatr. 2006;18(1):179-181.

31. Reisberg B, Doody R, Stoffler A, Schmitt F, Ferris S, Mobius HJ. A 24week open-label extension study of memantine in moderate to severe Alzheimer disease. Arch Neurol. 2006;63(1):49-54.

32. Winblad B, Jones RW, Wirth Y, Stoffler A, Mobius HJ. Memantine in moderate to severe Alzheimer's disease: a meta-analysis of randomized clinical trials. Dement Geriatr Cogn Disord. 2007;31(5):775-782.

33. Wilkinson D, Andersen HF. Analysis of the effect of memantine in reducing the worsening of clinical symptoms in patients with moderate to severe Alzheimer's disease. Dement Geriatr Cogn Disord. 2007;24(2):138-145.

34. Emre M, Mecocci P, Stender K. Pooled analyses on cognitive effects of memantine in patients with moderate to severe Alzheimer's disease. J Alzheimers Dis. 2008;14(2):193-199.

35. Rive B, Vercelletto M, Damier FD, Cochran J, Francois C. Memantine enhances autonomy in moderate to severe Alzheimer's disease. Int J Geriatr Psychiatry. 2004;19(4):458-464.

36. Paskavitz JF, Gunstad JJ, Samuel JE. Clock drawing and frontal lobe behavioral effects of memantine in Alzheimer's disease: a rater-blinded study. Am J Alzheimers Dis Other Demen. 2006;21(6): 449-454.

37. Gauthier S, Wirth Y, Mobius HJ. Effects of memantine on behavioural symptoms in Alzheimer's disease patients: an analysis of the Neuropsychiatric Inventory (NPI) data of two randomized, controlled studies. Int J Geriatr Psychiatry. 2005;20(5):459-464.

38. Ferris S, Schneider L, Farmer M, Kay G, Crook T. A double-blind, placebo-controlled trial of memantine in age-associated memory impairment (memantine in AAMI). Int $J$ Geriatr Psychiatry. 2007;22(5): 448-455.

39. Peskind ER, Potkin SG, Pomara N, et al. Memantine treatment in mild to moderate Alzheimer disease: a 24-week randomized, controlled trial. Am J Geriatr Psychiatry. 2006;14(8):704-715.

40. Porsteinsson AP, Grossberg GT, Mintzer J, Olin JT; Memantine MEM-MD-12 Study Group. Memantine treatement in patients with mild to moderate Alzheimer's disease already receiving a cholinesterase inhibitor: a randomized, double-blind, placebo-controlled trial. Curr Alzheimer Res. 2008;5(1):83-89.

41. Bakchine S, Loft H. Memantine treatment in patients with mild to moderate Alzheimer's disease: results of a randomized, double-blind, placebo-controlled 6-month study. J Alzheimers Dis. 2008;13(1): 97-107.
42. Mobius HJ, Stoffler A. Memantine in vascular dementia. Int Psychogeriatr. 2003;15 Suppl 1:207-213.

43. Orgogozo JM, Rigaud AS, Stoffler A, Mobius HJ, Forette F. Efficacy and safety of memantine in patients with mild to moderate vascular dementia: a randomized, placebo-controlled trial (MMM 300). Stroke. 2002;33(7):1834-1839.

44. Kavirajan H, Schneider LS. Efficacy and adverse effects of cholinesterase inhibitors and memantine in vascular dementia: a metaanalysis of randomized controlled trials. Lancet Neurol. 2007;6(9): 782-792.

45. Levin OS, Batukaeva LA, Smolentseva IG, Amosova NA. Efficacy and safety of memantine in dementia with Lewy bodies. Zh Nevrol Psikhiatr Im S S Korsakova. 2008;108(5):39-46.

46. Sabbagh MN, Hake AM, Ahmed S, Farlow MR. The use of memantine in dementia with Lewy bodies. J Alzheimer's Dis. 2005;7(4):285-289.

47. Ridha BH, Josephs KA, Rosser MN. Delusions and hallucinations in dementia with Lewy bodies: worsening with memantine. Neurology. 2005;65(3):481-482.

48. Schifitto G, Navia BA, Yiannoutsos CT, et al; Adult AIDS Clinical Trial Group (ACTG) 301;700 teams; HIV MRS Consortium. Memantine and HIV-associated cognitive impairment: a neuropsychological and proton magnetic resonance spectroscopy study. AIDS. 2007;21(14): 1877-1886.

49. Rustembegovic A, Kundurovic Z, Sapcanin A, Sofic E. A placebocontrolled study of memantinet (Ebixa) in dementia of WernickeKorsakoff syndrome. Med Arh. 2003;57(3):149-150.

50. Diehl-Schmid J. Forstl H, Perneczky R, Pohl C, Kurz A. A 6-month, open-label study of memantine in patients with frontotemporal dementia. Int J Geriatr Psychiatry. 2008;23(7):754-759.

51. Wenk GL, Danysz W, Mobley SL. MK-801, memantine and amantadine show neuroprotective activity in the nucleus basalis magnocellularis. Eur J Pharmacol. 1995;293(3):267-270.

52. Volbracht C, van Beek J, Zhu C, Blomgren K, Leist M. Neuroprotective properties of memantine in different in vitro and in vivo models of excitotoxicity. Eur J Neurosci. 2006;14(8):2611-2622.

53. Zhao X, Marszalec W, Toth PT, Huang J, Yeh JZ, Narahashi T. In vitro galantamine-memantine co-application: mechanism of beneficial action. Neuropharmacology. 2006;51(7-8):1181-1191.

54. Garibova TL, Voronina TA, Litvinova SA, Kuznetsova AL, Kul'chikov AE, Alesenko AV. Features of memantine action profile in cholinergic deficit and intracerebral posttraumatic hematoma (hemorrhagic stroke) models in rats. Eksp Klin Farmakol. 2008;71(2): 8-13.

55. More L, Gravius A, Nagel J, Valastro B, Greco S, Danysz W. Therapeutically relebant placma concentrations of memantine produce significant L-N-methyl-D-aspartate receptor occupation and do not impair learning in rats. Behav Pharmacol. 2008;19(7):724-734.

56. Stieg PE, Sathi S, Warach S, Le DA, Lipton SA. Neuroprotection by the NMDA receptor-associated open-channel blocker memantine in a photothrombotic model of cerebral focal ischemia in neonatal rat. Eur J Pharmacol. 1999;375(1-3):115-120.

57. Rao VL, Dogan A, Todd KG, Bowen KK, Dempsey RJ. Neuroprotection by memantine, a non-competitive NMDA receptor antagonist after traumatic brain injury in rats. Brain Res. 2001;911(1):96-100.

58. Liu C, Lin N, Wu B, Qiu Y. Neuroprotective effect of memantine combined with topiramate in hypoxic-ischemic brain injury. Brain Res. 2009;1282:173-182.

59. Sinn DI, Lee ST, Chu K, et al. Combined neuroprotective effects of celecoxib and memantine in experimental intracerebral hemorrhage. Neurosci Lett. 2007;411(3):238-242.

60. Rojas JC, Saavedra JA, Gonzalez-Lima F. Neuroprotective effects of memantine in a mouse model of retinal degeneration induced by rotenone. Brain Res. 2008;1215:208-217.

61. Ito Y, Nakamura S, Tanaka H, Shimazawa M, Araie M, Hara H. Memantine protects against secondary neuronal degeneration in lateral geniculate nucleus and superior colliculus after retinal damage in mice. CNS Neurosci Ther. 2008;14(3):192-202. 
62. Culmsee C, Junker V, Kremers W, Thal S, Plesnila N, Krieglstein J. Combination therapy in ischemic stroke: synergistic neuroprotective effects of memantine and clenbuterol. Stroke. 2004;35(5): 1197-1202.

63. Jung KH, Chu K, Lee ST, et al. Augmentation of nitrite therapy in cerebral ischemia by NMDA receptor inhibition. Biochem Biophys Res Commun. 2009;378(3):507-512.

64. Lapchak PA. Memantine, an uncompetitive low affinity NMDA open-channel antagonist improves clinical rating scores in a multiple infarct embolic stroke model in rabbits. Brain Res. 2006;1088(1): 141-147.

65. Battista MA, Hierholzer R, Khouzam HR, Barlow A, O-Toole S. Pilot trial of memantine in the treatment of posttraumatic stress disorder. Lancet Neurol. 2007;6(9):782-792.

66. Fischer PA, Jacobi P, Schneider E, Schonberger B. Effects of intravenous administration of memantine in parkinsonian patients. Arzneimittelforschung. 1977;27(7):1487-1489.

67. Schneider E, Fischer PA, Clemens R, Balzereit F, Funfgeld EW, Haase HJ. Effects of oral memantine administration on Parkison symptoms. Results of a placebo-controlled multicenter study. Dtsch Med Wochenschr. 1984;109(25):987-990.

68. Merello M, Nouzeilles MI, Cammarota A, Leiguarda R. Effect of memantine (NMDA antagonist) on Parkinson's disease: a doubleblind crossover randomized study. Clin Neuropharmacol. 1999;22(5): 273-276.

69. Nikolajsen L, Gottrup H, Kristensen AG, Jensen TS. Memantine (a N-methy-D-aspartate receptor antagonist) in the treatment of neuropathic pain after amputation or surgery: a randomized, double-blinded, cross-over study. Anesth Analg. 2000;91(4):960-966.

70. Sang CN, Booher S, Gilron I, Parada S, Max MB. Dextromethorphan and memantine in painful diabetic neuropathy and postherpetic neuralgia: efficacy and dose-response trials. Anesthesiology. 2002;96(5):1053-1061.

74. Schifitto G, Yiannoutsos CT, Simpson DM, et al; Adult AIDS Clinical Trials Group (ACTG) 301 Team. A placebo-controlled study of memantine for the treatment of human immunodeficiency virus-associated sensory neuropathy. J Neuroviol. 2006;12(4):328-331.

72. Schley M, Topfner S, Wiech K, et al. Continuous brachial plexus blockade in combination with the NMDA receptor antagonist memantine prevents phantom limb pain in acute traumatic upper limb amputees. Eur J Pain. 2007;11(3):299-308.

73. Maier C, Dertwinkel R, Mansourian N, et al. Efficacy of the NMDAreceptor antagonist memantine in patients with chronic phantom limb pain - results of a randomized double-blinded, placebo-controlled trial. Pain. 2003;103(3):277-283.

74. Wiech K, Kiefer RT, Topfner S, et al. A placebo-controlled randomized crossover trial of the N-methyl-D-aspartate acid receptor antagonist, memantine, in patients with chronic phantom limb pain. Anesth Analg. 2004;98(2):408-413.

75. Sinis N, Birbaumer N, Gustin S, et al. Memantine treatment of complex regional pain syndrome: a preliminary report of six cases. Clin J Pain. 2007:23(3):237-243.

76. Bigal M, Rapoport A, Sheftell F, Tepper D, Tepper S. Memantine in the preventive treatment of refractory migraine. Headache. 2008;48(9):1337-1342.

77. Muhonen LH, Lonnqvist J, Juva K, Alho H. Double-blind, randomized comparison of memantine and excitalopram for the treatment of major depressive disorder comorbid with alcohol dependence. J Clin Psychiatry. 2008;69(3):392-399.

78. Ferguson JM, Shingleton RN. An open-label, flexible-dose study of memantine in major depressive disorder. Clin Neuropharmacol. 2007;30(3):136-144.

79. Brennan BP, Roberts JL, Fogarty KV, Reynolds KA, Jonas JM, Hudson JI. Memantine in the treatment of binge eating disorder: an open-label, prospective trial. Int J Eat Disorder. 2008;41(6): $520-526$.
80. Krivoy A, Wizman A, Laor L, Hellinger N, Zemishlany Z, Fischel T. Addition of memantine to antipsychotic treatment in schizophrenia inpatients with residual symptoms: A preliminary study. Eur Neuropsychopharmacol. 2008;18(2):117-121.

81. Cerullo MA, Adler CM, Strakowski SM, Eliassen JC, Nasrallah HA, Nasrallah AT. Memantine normalizes brain activity in the inferior frontal gyrus: a controlled pilot fMRI study. Schizophr Res. 2007; 97(1-3):294-296.

82. Niederhofer H. Glutamate antagonists seem to be slightly effective in psychopharmacologic treatment of autism. J Clin Psychopharmacol. 2007;27(3):317-318

83. Chez MG, Burton Q, Dowling T, Chang M, Khanna P, Kramer C. Memantine as adjunctive therapy in children diagnosed with autistic spectrum disorders: an observation of initial clinical response and maintenance tolerability. J Child Neurol. 2007;22(5):574-579.

84. Findling RL, McNamara NK, Stansbrey RJ, et al. A pilot evaluation of the safety, tolerability, pharmacokinetics, and effectiveness of memantine in pediatric patients with attention-deficit/hyperactivity disorder combined type. J Child Adolesc Psychopharmacol. 2007;17(1): 19-33.

85. McLean R, Proudlock F, Thomas S, Degg C, Gottlob I. Congenital nystagmus: randomized, controlled, double-masked trial of memantine/ gabapentin. Ann Neurol. 2007;61(2):130-138.

86. Ondo WG, Mejia NI, Hunter CB. A pilot study of the clinical efficacy and safety of memantine for Huntington's disease. Parkinsonism Relat Disord. 2007;13(7):453-454.

87. Beister A, Kraus P, Kuhn W, Dose M, Weindl A, Gerlach M. The $\mathrm{N}$-methyl-D-aspartate antagonist memantine retards progression of Huntington's disease. J Neural Transm Suppl. 2004;(68): $117-122$.

88. Bisaga A, Comer SD, Ward AS, Popik P, Kleber HD, Fischman MW. The NMDA antagonist memantine attenuates the expression of opioid physical dependence in humans. Psychopharmacology. 2001;157(1):1-10.

89. Figueiredo RR, Langguth B, Mello de Oliveira P, Aparecida de Azevedo A. Tinnitus treatment with memantine. Otolaryngol Head Neck Surg. 2008;138(4):492-496.

90. Collins ED, Vosberg SK, Ward AS, Haney M, Foltin RW. The effects of acute pretreatment with high-dose memantine on the cardiovascular and behavioral effects of cocaine in humans. Exp Clin Psychopharmacol. 2007; 15(3):228-237.

91. Vosburg SK, Hart CL, Haney M, Foltin RW. An evaluation of the reinforcing effects of memantine in cocaine-dependent humans. Drug Alcohol Depend. 2005;79(2):257-260.

92. Thuerauf N, Lunkenheimer J, Lunkenheimer B, et al. Memantine fails to facilitate partial cigarette deprivation in smokers - no role of memantine in the treatment of nicotine dependency? J Neural Transm. 2007;114(3):351-357.

93. Zarate CA Jr, Singh JB, Quiroz JA, et al. A double-blind, placebocontrolled study of memantine in the treatment of major depression. Am J Psychiatry. 2006;163(1):153-155.

94. Evans SM, Levin FR, Brooks DJ, Garawi F. A pilot double-blind treatment of memantine for alcohol dependence. Alcohol Clin Exp Res. 2007;31(5):775-782.

95. Muhonen LH, Lahti J, Sinclair D, Lonnqvist J, Alho H. Treatment of alcohol dependence in patients with co-morbid major depressive disorder - predictors for the outcomes with memantine and escitalopram medication. Subst Abuse Treat Prev Policy. 2008;(3):20.

96. ClinicalTrials.gov [homepage on the internet]. Maryland: U.S. National Library of Medicine; c1993-2008 [updated 2009 June 2; cited 2009 June 15]. http://www.clinicaltrials.gov/.

97. Grossberg GT, Manes F, Allegri R, et al. A multinational, randomized, double-blind, placebo-controlled, parallel-group trial of memantine extended-release capsule ( $28 \mathrm{mg}$, once daily) in patients with moderate to severe Alzheimer's disease. [poster] 133rd Annual Meeting of the American Neurological Association. September 21-24, 2008; Salt Lake City, UT, USA. 
98. Jones RW, Bayer A, Inglis F, Barker A, Phul R. Safety and tolerability of once-daily versus twice-daily memantinet: a randomized, doubleblind study in moderate to severe Alzheimer's disease. Int J Geriatr Psychiatry. 2007;22(3):258-262.

99. Ott BR, Blake LM, Kagan E, Resnick M; for the Memantine MEM-MD-11AB Study Group. Open label, multicenter, 28-week extension study of the safety and tolerability of memantine in patients with mild to moderate Alzheimer's disease. J Neurol. 2007;254(3): 351-358.
100. Frx.com [homepage on the internet]. Missouri: Forest Laboratories, Inc.; c2007 [updated 2007 April; cited 2009 June]. http://www.frx. com/pi/Namenda_pi.pdf/.

101. Rammes G, Rupprecht R, Ferrari U, Zieglgansberger W, Parsons CG. The N-methyl-D-aspartate receptor channel blockers memantine, MRZ 2/579 and other amino-alkyl-cyclohexanes antagonize 5-HT(3) receptor currents in cultured HEK-293 and N1E-115 cell systems in non-competitive manner. Neurosci Lett. 2001;306(1-2):81-84.

\section{Publish your work in this journal}

Clinical Interventions in Aging is an international, peer-reviewed journal focusing on evidence-based reports on the value or lack thereof of treatments intended to prevent or delay the onset of maladaptive correlates of aging in human beings. This journal is indexed on PubMed Central, MedLine, the American Chemical Society's 'Chemical

\section{Dovepress}

Abstracts Service' (CAS), Scopus and the Elsevier Bibliographic databases. The manuscript management system is completely online and includes a very quick and fair peer-review system, which is all easy to use. Visit http://www.dovepress.com/testimonials.php to read real quotes from published authors.

Submit your manuscript here: http://www.dovepress.com/clinical-interventions-in-aging-journal 